\title{
Steno and the Rock Cycle
}

Citation:A.H. Cutler (2021) Steno and the Rock Cycle. Substantia 5(1) Suppl.: 89-97. doi: 10.36253/Substantia-1280

Copyright: @ 2021 A.H. Cutler. This is an open access, peer-reviewed article published by Firenze University Press (http://www.fupress.com/substantia) and distributed under the terms of the Creative Commons Attribution License, which permits unrestricted use, distribution, and reproduction in any medium, provided the original author and source are credited.

Data Availability Statement: All relevant data are within the paper and its Supporting Information files.

Competing Interests: The Author(s) declare(s) no conflict of interest.

\author{
Alan H. Cutler \\ Department of Engineering, Physical and Computer Sciences, Montgomery College, 51 \\ Mannakee Street, Rockville, MD 20850 USA \\ E-mail: alan.cutler@montgomerycollege.edu
}

\begin{abstract}
Geologists categorize the basic types of rock according to their origin - igneous, sedimentary, or metamorphic - rather than by their physical properties. This is expressed dynamically by the fundamental concept of the rock cycle, which describes how the basic rock types are derived from one another within the Earth system as a result of ongoing cyclic geologic processes. In Nicolaus Steno's published geological work, particularly De Solido, he takes a similar approach, outlining how a substance can be examined "to disclose the place and manner of its production". Steno also recognizes the roles of erosion, transport, and deposition in the production of sedimentary strata from pre-existing Earth materials. His description and diagrams of the geological evolution of Tuscany also show a clear cyclicity of process. While the modern concept of the rock cycle did not emerge until the $19^{\text {th }}$ century, Steno's work contains key elements of this important concept.
\end{abstract}

Keywords: Geology, rock cycle, rock classification, Earth processes, Nicolaus Steno.

In his short scientific career, Nicolaus Steno produced two major works on geology. The first was an addendum to a 1667 report, Canis Carchariae dissectum caput ${ }^{1}$, on the dissection of a shark head that he performed in Florence for the court of Grand Duke Ferdinand II. In the addendum Steno argued for the organic origin of fossil shark's teeth and other marine fossils (a contentious issue at the time) and for the sedimentary origin of the enclosing rock. He followed Canis two years later with a more expansive work, De solido intra solidum naturaliter content dissertationis prodromus ${ }^{2}$, which was intended to be an abstract, or prodromus, for a much longer and more detailed study, but this full version never appeared.

Both Canis and De Solido include many acute observations on minerals, rocks, and fossils, but De Solido in particular is widely regarded as one of

\footnotetext{
${ }^{1}$ N. Steno, Canis Carchariae dissectum caput in Steno, N. Elementorum Myologiae Specimen: Florence, Stella, 1667, p. 90-110. (English translation in Steno Geological Papers (Ed: G. Scherz) Copenhagen, Odense University Press, 1969, pp. 66-131.

${ }^{2}$ N. Steno, De solido intra solidum naturaliter content dissertationis prodromus, Florence, Stella, 1669, 78p. English translation in Steno Geological Papers (Ed: G. Scherz) Copenhagen, Odense University Press, 1969, pp. 134-234.
} 
the founding documents of the science of geology. It is best known for what geologists today refer to as his principles of crystallography and stratigraphy. Both are staples of introductory geology classes and reflect the view shared by Steno and modern geologists that mineral crystals and the Earth as a whole are not static objects, but dynamic entities with a history of growth and development. In fact, his stratigraphic principles of superposition, original horizontality, and lateral continuity laid the logical foundation for historical geology and the exploration of deep time.

My purpose here is to explore how another key concept in modern geology also appears in De Solido, albeit in a rudimentary form. This is the so-called rock cycle, which describes how the materials of the Earth's crust are continuously being created, destroyed, transformed, and recycled by geologic processes operating within the Earth and on its surface. Some elements of this idea have a long history, extending back as far as classical times, and it did not fully take shape until the $19^{\text {th }}$ century with the work of Lyell and his contemporaries, so I make no claim here that Steno should be seen as the author of the rock cycle concept. Rather, this is an attempt to discern what elements of this important geological concept are present, and what are missing, in Steno's work, and the extent to which his conception of Earth processes can be considered a coherent rock cycle.

\section{THE ROCK CYCLE}

The cyclic view of Earth processes described by the rock cycle has deep historical roots. Aristotle and other classical writers observed marine fossils on land and in the rocks of mountains and proposed that there was a periodic interchange of land and sea ${ }^{3}$. The idea of cycles in Earth's history appears in the writings of Medieval writers in Europe and the Islamic world, as well as Renaissance thinkers such as Dante Alighieri, and Leonardo da Vinci ${ }^{4}$. Cyclicity was also a feature of several $17^{\text {th }}$ and $18^{\text {th }}$ century theories of the Earth ${ }^{5}$. These early "rock cycles" were primarily sedimentary. That is, they mostly considered cycles of erosion and deposition of sediment. Hutton is generally credited for giving igneous activity a significant role in his version of the cycle ${ }^{6}$. Metamor-

\footnotetext{
${ }^{3}$ A. Cutler, The Seashell on the Mountaintop, Dutton, New York 2003, pp. 8-9.; D. Oldroyd, Thinking About the Earth: A History of Ideas in Geology, Harvard, Cambridge, 1996, pp. 7-28

${ }^{4}$ Pp. 24, 27 in Ref. 3, (Oldroyd).

${ }^{5}$ See S.J. Gould, Time's Arrow, Time's Cycle, Harvard University, Cambridge, 1987, pp. 21-59 and F. Ellenberger, History of Geology, V. 2, Balkema, Rotterdam, 1999, pp. 209-231 for examples.

${ }^{6}$ J. Hutton, Theory of the Earth with Proofs and Illustrations, William Creech,
}

phism was later introduced by Lyell in his Principles of Geology 1833.

Figure 1 shows a simplified diagram of the rock cycle, as generally conceived today. The main points of reference are three basic classes of rock: igneous, sedimentary, and metamorphic. Each type of rock represents not just the material itself but the geological context and processes that produced it. Igneous rock forms as magma or lava cools and solidifies. Igneous rock formed from magma that solidifies in the Earth's interior is plutonic rock. Igneous rock formed from lava that solidifies on the Earth's surface after an eruption is called volcanic rock. Sedimentary rock forms from the raw material of its source rock, which undergoes weathering, transportation, deposition, and ultimately lithification. Metamorphic rock forms as pre-existing rock - igneous, sedimentary, or other metamorphic - in the Earth's interior is altered by heat and extreme pressure to create altered rock with new mineralogy and/or texture.

As will be discussed in more detail below, the modern rock cycle is far more complex than what Steno could have imagined in 1669. Accordingly, the following discussion will focus on three underlying aspects of the cycle that are implicit in Steno's work: 1) the classification of rock by its mode of origin (generative classification), 2) derivation of rock from pre-existing Earth materials, and 3) cyclicity of Earth processes.

\section{STENO AND GENERATIVE CLASSIFICATION}

Classifying materials by their history or origin is a hallmark of geologic thought and has been called "generative classification" by Hansen. ${ }^{8}$ It is different from the approach generally taken by ahistorical physical sciences such as chemistry or physics. A crystal of silicon dioxide (quartz) is silicon dioxide regardless of how, when, or where it formed, but geologists distinguish between a quartzose sandstone (sedimentary rock) and quartzite (metamorphic rock), even though their chemical makeup may be precisely the same.

Steno makes no attempt in De Solido to construct any system for describing or classifying rock, but he lays the foundation for the generative classification approach at the beginning of his De Solido as he lays out the general problem he aims to address:

\footnotetext{
Edinburgh, 1795. See ref 5 (Gould) for discussion Of Hutton's cycle. ${ }^{7}$ C. Lyell, Principles of Geology, V. 3, facsimile of first edition (1833), University of Chicago Press, 1991, pp. 374-379.

${ }^{8}$ J.M. Hansen, On the Origin of Natural History: Steno's Modern, but forgotten philosophy of science, in The Revolution in Geology from the Renaissance to the Enlightenment (Ed: G.D. Rosenberg) Geological Society of America Memoir 23, Boulder, 2009, pp. 159-178.
} 


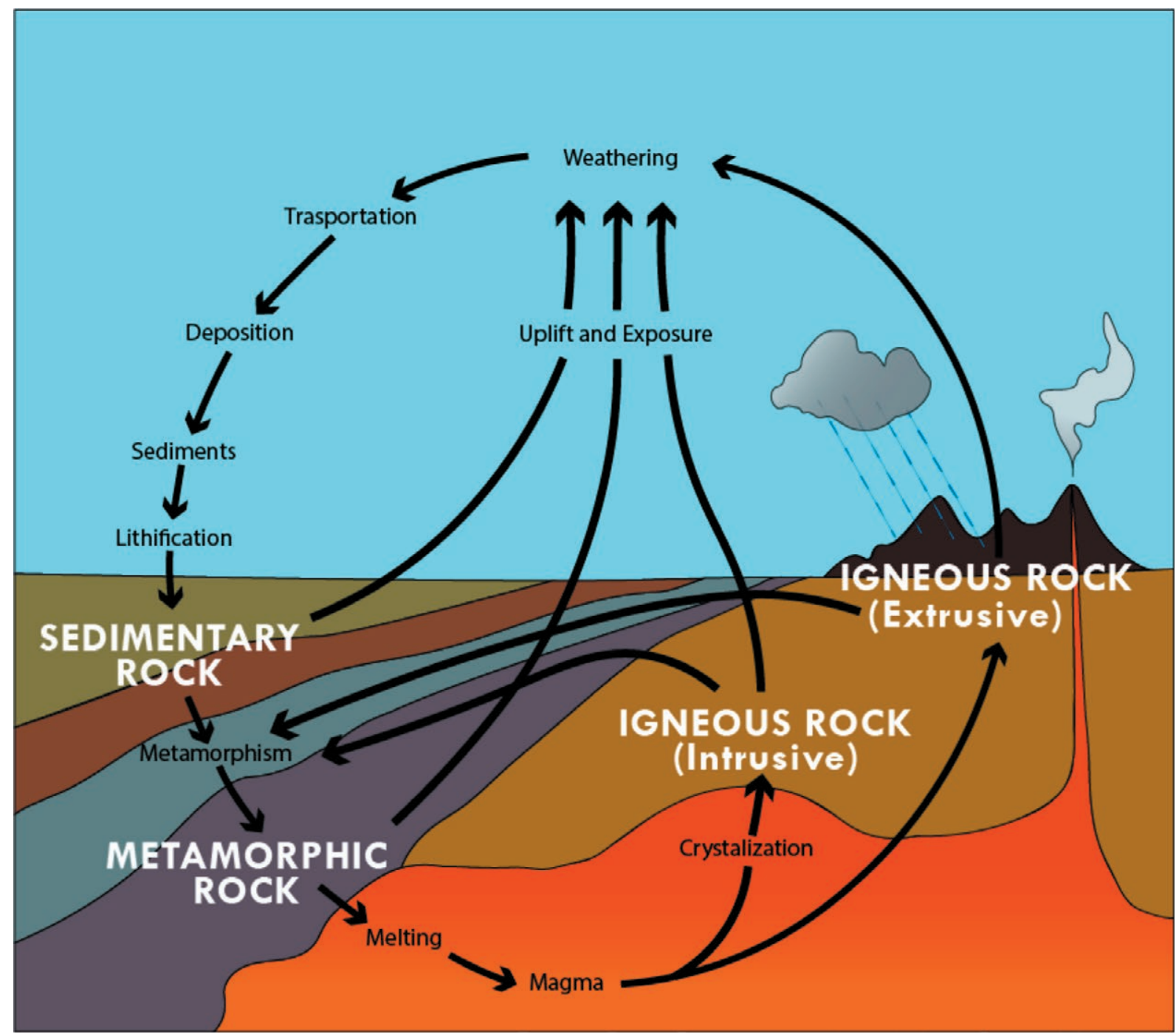

Figure 1. Typical depiction of the rock cycle. Arrows indicate processes and stages in the cycling between igneous, sedimentary, and metamorphic rock. See text for further explanation. Adapted from several sources by the author.

Given a substance endowed with a certain shape, and produced according to the laws of nature, to find in the substance itself clues disclosing the place and manner of its production. ${ }^{9}$

Gould ${ }^{10}$ argued that one of Steno's most momentous insights in De Solido was his decision, as Gould put it, "to arrange solids within solids according to the causes

\footnotetext{
${ }^{9}$ P. 141 in Ref 2 (Scherz). Steno's reasoning here applies a method now termed "abduction", in which the most likely explanation is sought for a given set of observations. See J.E.H.Smith, Thinking from Traces: Nicolas Steno's Palaeontology and the Method of Science, in Steno and the Philosophers (Eds.: R. Andrault, R., M. Lærke M.), Brill, Leiden, 2018, pp. $177-200$.

${ }^{10}$ S.J. Gould, Hen's Teeth and Horses Toes, Norton, New York, 1984, pp. 69-78.
}

that fashioned them". Gould saw Steno's "great taxonomic insight" as the key to the long-standing puzzle of fossils: were they the true remains of ancient organisms or merely simulacra created by vegetative forces within the Earth? Steno recognized that organic and inorganic bodies in rock necessarily differed in their place and manner of production. To discern the different origins of solids, Steno offered two propositions:

I. If a solid body is enclosed on all sides by another solid body, the first of the two to harden was that one which, when both touch, transferred its own surface characteristics to the surface of the other. ${ }^{11}$

\footnotetext{
${ }^{11}$ P. 151 in Ref 2 (Scherz)
} 
and

II. If a solid body resembles another solid body in all respects, not only in the state of its surface but also in the internal arrangement of the parts and particles, it will resemble it also in the method and place of production. ${ }^{12}$

The first is often referred to as the Principle of Molding ${ }^{13}$ and the second as the Principle of Sufficient Similarity ${ }^{14}$ or the Recognition Criterion. ${ }^{15}$

For organic bodies such as mollusk shells, their place of production was outside of the rock matrix that entombed them, or within the matrix, but while it was still soft and unlithified. Because their growth was unimpeded by a solid matrix, they invariably showed their characteristic shapes and ornaments without regard to the enclosing material. For inorganic bodies such as mineral crystals and metallic ore deposits, their place of production was within the solid rock matrix, or within fractures and voids within the rock. Growing in $s i t u$, their shapes were often constrained by the space available, and so did not show the same consistency as organic bodies. ${ }^{16}$

As for manner of production, Steno added a third proposition:

III. If a solid body was produced according to the laws of nature, it was produced from a fluid. ${ }^{17}$

Steno applied this principle to distinguish organic fossils from inorganic mineral growths, ${ }^{18}$ but he applied it with even more force to rocks and rock strata. In Canis he discusses the aqueous origin of sedimentary deposits at length. ${ }^{19}$ In De Solido, Steno follows his proposition of the Principle of Sufficient Similarity with this declaration:

The strata of the earth agree, in location and manner of production, with those strata that are deposited from turbid water. $^{20}$

\footnotetext{
${ }^{12}$ P. 151 in Ref 2 (Scherz)

${ }^{13}$ Ref 5 (Gould)

${ }^{14}$ Ref 5 (Gould)

${ }^{15}$ Ref 3 (Hansen)

${ }^{16}$ Pp. $111-113$ in Ref 1 (Scherz)

${ }^{17}$ P. 153 in Ref 2 (Scherz)

${ }^{18}$ In De Solido he argued that organic solids such as mollusk shells grow by addition of material from internal fluids delivered to growing surfaces through pores. In contrast, mineral crystals and other inorganic substances grow by addition of material to their external surfaces from external fluids. Steno rejects the idea that crystals grow "vegetatively," as others had speculated.

${ }^{19}$ Pp. $99-109$ in Ref 1 (Scherz)

${ }^{20}$ P. 151 in Ref 2 (Scherz)
}

This relates, of course, to the origin of sedimentary rock, which is the type of rock Steno primarily observed in Tuscany and is the type that most commonly contains fossils. In both Canis and De Solido he describes graded bedding, the arrangement of sedimentary grains resulting from rapid settling from turbid water, in which larger particles (the first to settle out) are overlain by increasingly fine particles (which settle out more slowly). His description in Canis of the depositional process is particularly lucid:

If we believe that the water under discussion could receive muddy water, either from the ocean or from torrents, it is certain that the bodies which make the water muddy ought to sink to the bottom when the violent motion ceases. Nor do we need to seek diligently for examples of this type, since both the beds of rivers and their estuaries give sure proof of it. One thing should be noted here, - the bodies that make the water muddy are not all the same weight; thus it follows that, as the water gradually calms down, first the heavier particles then the less heavy ones settle out; the lightest particles, however, float longer in the vicinity of the bottom before becoming attached to it. It is clear, in consequence, that frequently different layers will be found in the same sediment. ${ }^{21}$

\section{He also mentions it in De Solido:}

The larger bodies constrained in these same strata obey for the most part the laws of gravity, not only with respect to the position of any individual body but also the relative positions of different bodies to each other. ${ }^{22}$

Steno also applies the Principle of Sufficient Similarity to sedimentary rock strata in recognizing "place" of production in the sense of sedimentary environment. A marine environment would be indicated by "traces of sea salt, the remains of marine animals, timbers of ships and substances similar to the sea bed" ${ }^{23}$ On the other hand, strata containing terrestrial bodies such as pine cones and tree branches would have been laid down by "a river in flood or by a torrential outbreak", that is, in a fluvial environment. ${ }^{24}$

Steno recognizes another aspect of the place of production, that is, whether a sedimentary particle con-

\footnotetext{
${ }^{21}$ P. 105 in Ref 1 (Scherz)

${ }^{22}$ P. 161 in Ref 2 (Scherz). Geologists frequently use graded bedding within sedimentary rock strata to interpret tectonically tilted and overturned rock units, as it indicates the original "up" direction in contorted beds. Given Steno's invocation of gravity, it is possible that his observations of graded bedding in Tuscan strata were instrumental in his formulation of the stratigraphic principle of original horizontality. Any graded bedding he observed in inclined strata would have required him to mentally rotate the strata to a horizontal orientation.

${ }^{23}$ P. 163 in Ref 2 (Scherz)

${ }^{24}$ P. 163 in Ref 2 (Scherz)
} 
tained within sedimentary rock was produced elsewhere and transported to the site of deposition or produced in situ (allochthonous or autochthonous, respectively, in modern terminology).

Sediments are then formed when the contents of a fluid sink under their own weight regardless of whether these contents have been conveyed there from elsewhere or have been secreted gradually from particles of the fluid itself, either in its upper surface or from all the particles of fluid". ${ }^{25}$

In effect, Steno appears to recognize the distinction between detrital and chemical sediments. He further notes that autochthonous chemically deposited bodies can be eroded and deposited elsewhere as allochthonous detrital grains. Referring to agates, he writes "incrustations of this kind are often found away from the place of production because the material of the place has been scattered by the bursting of the strata", ${ }^{26}$ the abraded surfaces of these clasts in deposits being the clue to their allochthonous origin.

The Principle of Molding is applied by modern geologists when determining the allochthony or autochthony of sedimentary grains. Allochthonous mineral grains, such as sand grains or pebbles and other larger clasts in detrital rocks, are solid before deposition, so they commonly retain their original shape and do not interlock as the sediment is compacted and lithified. But autochthonous cement minerals that form in situ after deposition during lithification fill in the pore spaces between the allochthonous grains, creating an interlocking crystalline mass that binds the rock together and conforms to the shape of the pre-existing grains. This clastic texture in detrital sedimentary rock, with allochthonous clasts bound together by autochthonous cement, is distinct from the crystalline texture of chemical sedimentary rock such as rock salt or igneous rock such as granite, in which the mineral crystals are dominantly autochthonous and intergrow with one another as the minerals either precipitate from aqueous solution or crystallize from cooling magma. The Principle of Molding applies here as well: later-growing crystals fill in the spaces between earlier-growing crystals and take their shape from these spaces, allowing the sequence of crystal growth to be determined.

Geologists apply all three of Steno's principles in describing and classifying rock according to its origin, but nearly missing from Steno's discussion is rock that could be described as metamorphic or igneous. The absence of metamorphic rock from Steno's geology is not surprising;

\footnotetext{
${ }^{25}$ P. 161 in Ref 2 (Scherz)

${ }^{26}$ P. 161 in Ref 2 (Scherz)
}

it was not recognized as a distinct form of rock until the $19^{\text {th }}$ century. Further, metamorphic rock does not form from a fluid, the transformations that create it occur in the solid state. But igneous rock does form from a fluid - magma. Though Steno makes a brief allusion to volcanoes in his discussion of the origin of mountains, where he writes that mountains can form from "the eruption of fires that belch forth ashes and stones together with sulphur and bitumen"27, nowhere does he mention rock or any solids forming from molten fluids. This is somewhat surprising, given that as a goldsmith's son he would have been familiar with molten metals. He was certainly aware of writing on volcanoes by Kircher and others, and he traveled to Elba where he would have had the opportunity to observe granite in outcrop. We can only speculate whether his planned dissertation to follow up De Solido would have included a discussion of igneous rock.

\section{DERIVATION OF ROCK FROM PRE-EXISTING MATERIALS}

According to the rock cycle, all rock in the Earth's crust is derived from pre-existing materials which have a history that extends backward in time to the formation of the Earth. This is an idea implicit in much of De Solido, where Steno discusses the origins of detrital sedimentary rock and attempts in its last section to lay out a geological history of Tuscany, going back to the primordial strata at the time of Creation. He makes it explicit in a later sermon:

This holds for diamonds and all precious stones whose matter certainly was created at the beginning of time with the other material of the universe, and was mixed with the other particles of solid and fluid bodies until, after the destruction of the earth it was secreted in old subterranean caves and took shape now to be used by human toil to be used for its own purposes. ${ }^{28}$

In the sermon, Steno's intention is not scientific, but theological - he attributes minerals "not created by God, but after the malediction of earth" to the curse on Adam after the Fall. ${ }^{29}$ The concept of a history of recycling behind geological materials is clear enough, however.

In De Solido Steno describes a fossil shell he recognized as having been reworked from a deposit older than the deposit where it was found:

\footnotetext{
${ }^{27}$ P. 167 in Ref 2 (Scherz)

${ }^{28}$ Steno, N. "Ornaments, Monuments, Signs, Arguments" in Steno Geological Papers (Ed: G. Scherz) Copenhagen, Odense University Press, 1969, p. 251.

${ }^{29}$ P. 251 in Ref 23 (Scherz)
} 
A shell, partly destroyed internally, in which a marble incrustation, covered by various balanoids, had replaced the substance eaten away; thus it is possible to conclude with certainty that the shell had been left upon the land by the sea, then carried down to the sea, covered again by a new deposit and abandoned by the sea. ${ }^{30}$

He bases this conclusion on his taphonomic observations that the shell had diagenetic features (the marble encrustation, which implied previous burial and lithification) that were overlain by marine barnacles (balanoids), implying a second exposure in a marine environment before ultimate burial in the sedimentary stratum in which it was found.

Not only are fossils recycled and preserved, but rock particles can be as well. Steno notes that "fragments of another stratum" can be found in a stratum, making it "certain that the said stratum must not be counted among the strata that settled out of the first fluid at the time of Creation".

\section{CYCLICITY OF EARTH PROCESSES}

Two aspects of the cyclicity of Earth processes as described in the modern rock cycle deserve mention. The first is that the rock cycle has no set time frame. That is, the stages or transitions described in the cycle can occur over time scales ranging from very short (days, or even less) to very long (billions of years). Erupted volcanic ash can become "sediment" virtually instantly upon eruption, whereas plutonic igneous rock can remain uneroded and unmetamorphosed for billions of years. This lack of a regular time frame distinguishes it from many familiar cycles in science, such as astronomical and seasonal biological cycles. More to the point for the discussion here, though, is that this lack of a set time frame distinguishes the question of the cyclicity of Earth processes from the question of the cyclicity of time itself. The conflict between cyclic models of time (as conceived by Aristotle, for example) and linear models of time (as laid out in the Bible) has been discussed a length elsewhere. ${ }^{31}$ While a cyclic model of time necessarily implies a cyclicity of processes, linear models of time can also easily accommodate subordinate cyclicity. For this reason, Steno's religious faith and commitment to the Biblical narrative of Creation would have posed no necessary impediment to his acceptance of cyclic processes.

\footnotetext{
${ }^{30}$ Pp. 195-197 in Ref 2 (Scherz)

${ }^{31}$ S. Toulmin and J. Goodfield, The Discovery of Time, University of Chicago, Chicago, 1982, 280 p.; S.J. Gould, Time's Arrow, Time's Cycle, Harvard University, Cambridge, 1987, 222 p.; and many others.
}

A second aspect of the rock cycle is that it does not necessarily follow the set sequence shown by the outer circle of arrows in the Figure 1. Igneous rock is not inevitably eroded to create sediments and sedimentary rock, sedimentary rock is not inevitably altered to become metamorphic rock, and, finally, metamorphic rock is not inevitably melted to create magma and igneous rock. As the arrows passing through the circle illustrate, rock of any type at any stage of the cycle can be uplifted and weathered to produce sediments, and igneous rock can be altered to become metamorphic rock without any intermediate conversion to sediment or sedimentary rock. Finally, though not shown on the diagram, igneous rock can be re-melted to create magma which then crystallizes into new igneous rock, and, similarly, metamorphic rock can be "re-metamorphosed" by changing conditions to make new metamorphic rock.

As discussed above, Steno makes no mention of the igneous and metamorphic elements of the rock cycle, aside from some passing references to fire and heat. For this reason, the kinds of transformations and cycleswithin-cycles possible within the modern cycle do not appear in Steno's version of the cycle. It is essentially a sedimentary rock cycle.

The part of the sedimentary rock cycle that Steno devotes most of his attention to in De Solido is sedimentation, including the formation of graded bedding, as discussed above. Oddly, despite his emphasis on the hardening of sediments into rock in his Principle of Molding, Steno offers no account of lithification, besides a few scattered hints. In Canis he describes precipitation of dissolved bodies from transparent liquids to produce solids and observes that lime and gypsum can bind together fossil shells. ${ }^{32}$ In De Solido, following his proposition that all solids are produced from fluids, he discusses at length the growth of mineral crystals, incrustations and organic tissues but makes no clear reference to either the compaction of sediments or the cementation of sedimentary grains.

The next stage of the rock cycle, in which rock buried within the crust becomes exposed to surface weathering and erosion, gets more attention from Steno. This stage happens either by uplift, raising marine strata above sea level, for example, or by a drop in sea level, exposing the former sea bottom to subaerial weathering and erosion. Either way, whether it is the land that rises or the water level that drops, this is a key step in the rock cycle. It makes the rock available to become broken down to become sediment and ultimately new sedimentary rock. Steno describes both uplift and sea level change in De Solido.

\footnotetext{
32 Pp. 105-109; p. 97 in Ref 1 (Scherz)
} 
Steno states that "mountain peaks can be raised and lowered"33, attributing their formation mainly to the "alteration in the position of strata". ${ }^{4}$ How does this happen? Steno proposes two mechanisms:

The first way is the violent upheaval of strata, whether this be due mainly to a sudden flare of subterranean gases or to a violent explosion of air caused by other great subsidences nearby. This upward thrust of strata is followed by the dispersal of earthy material as dust and the shattering of rock material into pebbles and rough fragments. ${ }^{35}$

and

The second way is a spontaneous slipping or subsidence of the upper strata after they have begun to crack because of the withdrawal of the underlying substance of foundation; in consequence the broken strata take up different positions according to the variety of cavities and cracks. ${ }^{36}$

In his second mechanism, the relative uplift and tilting of rock strata can be the result of collapse of cavities within the Earth ${ }^{37}$. This would not in itself raise the overall elevation of the rock strata, but it would create a more irregular land surface, with local highs creating mountains. Steno suggests that progressive internal collapse over time has made land surface more irregular:

It is completely uncertain what the depth of the valleys was at the beginning of the deluge; but reason persuades us that, in the first centuries of the world's existence, cavities were gnawn [sic] out by water and by fire, so that slight collapse of strata followed from this; however, the highest mountains, of which Scripture mentions, were the highest mountains then found, not the highest of those observed in the present day. ${ }^{38}$

As for sea level fall, the collapse of caverns described above could also open passageways into the Earth for surface water to drain, thus lowering sea level. This is the hypothesis Steno favors.

Who has investigated the structure of the interior of the

\footnotetext{
${ }^{33}$ P. 169 in Ref 2 (Scherz)

${ }^{34}$ P. 167 in Ref 2 (Scherz)

${ }^{35}$ P. $165-167$ in Ref 2 (Scherz)

${ }^{36} \mathrm{P} .167$ in Ref 2 (Scherz)

${ }^{37}$ Descartes also invoked crustal collapse as mechanism for producing relief on the Earth's surface in his Principia Philosophiae, Amsterdam. Apud Ludovicum Elzerverium, 1644. See Ref 3 pp. 45-47 (Oldroyd) for a description of Descartes' model.

${ }^{38}$ P. 207 in Ref 2 (Scherz). Steno illustrates these inferred caverns De Solido in his depiction of the evolution of Tuscany (21 and 24 in Figure 2), discussed below.
}

earth and will dare deny the possible existence of huge spaces there, at times filled with aqueous fluid, at other times filled with aerial fluid? ${ }^{39}$

As for a subsequent rise in sea level that precedes the next cycle of sedimentation, Steno's mechanism is more complex. He proposes that volumes of water in the Earth's subterranean chambers could be heated by internal fires, causing it to be expelled to the atmosphere and fall as rain, which would then presumably cause the oceans to overflow onto the land. He also suggests that the bottom of the sea could be "raised up by the expansion of subterranean caverns." ${ }^{\prime 0}$ This may be reference to the hypothesis of the Greek Geographer Strabo, who in an effort to explain marine shells found on land suggested that periodic upward flexing of the sea floor could displace ocean water and thus raise sea level. ${ }^{41}$

Rock strata uplifted and exposed, by whatever mechanism, are then weathered to produce sediment, which is eroded and transported to its site of deposition. The first step, the slow breakdown of rock by weathering, is not directly addressed by Steno. In De Solido, he attributes the "dispersal of earthy material as dust and the shattering of rock into pebbles and rough fragments" to the "violent upheaval" and "upward thrust" of rock strata. ${ }^{42}$

Sediment transportation is described by Steno in De Solido in several passages, emphasizing the "great quantity of earth" carried to the sea every year by rivers and "innumerable torrents. ${ }^{43}$ Steno sees this as an ongoing process, with new sediment "added daily" to coastal deposits. This completes Steno's cycle, with these deposits potentially forming new rock strata.

\section{CYCLES IN THE GEOLOGICAL EVOLUTION OF TUSCANY}

Figure 2 shows Steno's conception of the geological evolution of Tuscany, which represents two cycles of sedimentation in six "aspects". Two aspects (22 and 25) represent marine deposition, two (21 and 24) represent the hollowing out of subterranean caverns (perhaps associated with the draining away of surface waters and the drop in sea level), and two (20 and 23) represent the collapse and shifting of strata to produce an uneven landscape.

Steno describes the first episode of deposition (25 in Figure 2) as occurring when "everything was cov-

\footnotetext{
${ }^{39}$ P.207 in Ref 2 (Scherz)

${ }^{40}$ P.209 in Ref 2 (Scherz)

${ }^{41}$ F. Ellenberger, History of Geology, V1, Balkema, Rotterdam, 1996, p. 22

${ }^{42}$ P.165-167 in Ref2 (Scherz)

${ }^{43}$ P.209-211 in Ref 2 (Scherz)
} 


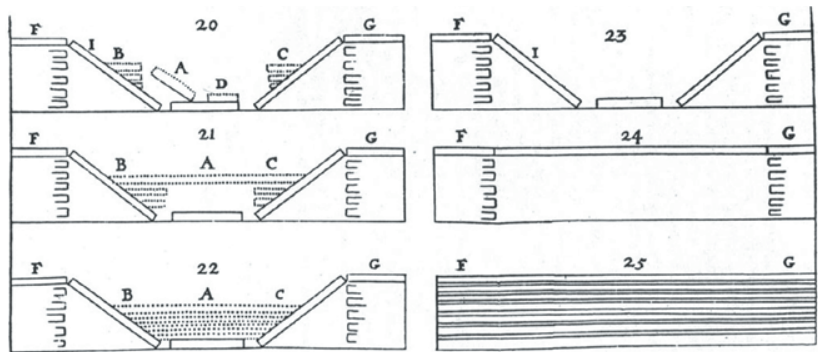

Figure 2. Steno's diagram of the geologic history of Tuscany in De Solido, showing two cycles of sedimentation and mountain-building. Time sequence goes from lower right (25) to upper left (20) in reverse numeric sequence. From Reference 2 (Steno).

ered by water" ${ }^{\prime 4}$, as described in Genesis. These strata were deposited by the first fluid "devoid of plants, animals, and other solids." He does allow the possibility that younger strata containing "various bodies" might in some places lie unconformably above the primal strata laid down by the first fluid, but these younger strata are not shown in the diagram. Also not shown in the diagram is any indication of a source for the sediments in these original strata. In a time when the entire world was covered by water, there would have been no exposed land to supply detrital sediments. It may be that Steno conceived these sediments as being chemical sediments derived from materials dissolved in the first fluid at Creation. In fact, the actual strata corresponding to those in the diagram are detrital turbidite sediments, consisting of well-sorted, fine-grained sands, which Steno likely saw in his travels around Tuscany. ${ }^{45}$ The uniformity and fine size of the sediments, and the lack of visible fossils, convinced Steno of their primordial origin. Earlier in $D e$ Solido he writes:

If all particles in a stony stratum are observed to be of the same nature and of fine size, it cannot reasonably be denied that this stratum was produced at the time of Creation from a fluid that then covered all things: Descartes, too, accounts for the origin of the earth's strata in this way. ${ }^{46}$

The second episode of deposition (22 in Figure 2) Steno attributes to the Deluge. Steno notes that mountains existed at that time, according to Scripture. The diagram shows first-cycle rock strata (F-G in Figure 2) at higher elevations than strata (B-A-C) deposited

${ }^{44}$ P. 205 in Ref 2 (Scherz)

${ }^{45}$ S. Dominici, Journal of Mediterranean Earth Sciences, 2009, 1, 101110.

${ }^{46}$ P. 163 in Ref 2 (Scherz). Steno's mention of Descartes refers to the model presented in Ref 33 (Descartes). In Descartes' model the solid particles producing the Earth's strata are "corpuscles" of matter, rather than sedimentary grains. during the second cycle, so these presumably provided the source for these sediments. It is less clear, however, if Steno intends that all these strata formed during that single event, because in several places in De Solido he explicitly considers multiple marine incursions into Tuscany. Marine strata containing the "timbers of ships" ${ }^{\prime 4}$ are clearly post-Diluvial, and Steno cites approvingly the ancient accounts of "earth movements, eruptions of fires from the earth, flooding by rivers and seas" as demonstrating that "many and various changes have occurred in four thousand years" since the Deluge. ${ }^{48}$ It would appear then, that while Steno is careful to reconcile his scenario with Scripture, he conceives his rock cycle as not only a natural, but an ongoing process.

\section{CONCLUSION}

In Steno's geological works, Canis and De Solido, he lays out the elements of a functional, if in modern terms incomplete, rock cycle. Missing, of course, are igneous and metamorphic rocks, and he also gives little attention to the processes of lithification and weathering. However, the three key aspects of the rock cycle mentioned above are well-represented in Steno's work, especially in De Solido:

1. Classification of rock by its mode of origin (generative classification). Steno introduces this idea at the outset of De Solido, and he applies it in both works to argue for the sedimentary origin of rock strata, as well as to make the distinction between chemical and detrital sediments, and to discern sedimentary environments of strata. His principles of Molding and Sufficient Similarity, which form the basis of generative classification, would later find application to other rock types as well, such as plutonic igneous and metamorphic, of which Steno was unaware but are fundamental parts of the modern rock cycle.

2. Derivation of rock from pre-existing Earth materials. Steno is clear that sedimentary strata can be composed of recycled material eroded from older rock. Moreover, his principles of reasoning allowed him to recognize this material in strata. In contrast with modern understanding, however, he considers the oldest exposed rocks in Tuscany to be primordial and therefore a product of the original Creation.

3. Cyclicity of process. In De Solido Steno proposes natural mechanisms for uplift and sea level change. He also describes ongoing processes of erosion, transport,

${ }^{47}$ P. 163 in Ref 2 (Scherz)

${ }^{48}$ P. 211 in Ref 2 (Scherz) 
and sedimentation. Further, in his outline of Tuscany's geologic history, he recognizes two major cycles of sedimentation, and hints at later, smaller-scale cycles.

Steno's stated purpose in De Solido was to account for the existence of solid bodies, such as fossils and mineral crystals, inside of solid rock, not to create an overarching theory of the Earth. Still, despite some gaps and inaccuracies, Steno's rock cycle as it appears in his work, supported by his principles of Molding and Sufficient Similarity, constituted a forerunner of the modern rock cycle concept.

\section{ACKNOWLEDGEMENTS}

I want to thank Stefano Dominici for organizing the 2019 symposium, "Galilean Foundation for a Solid Earth 1669-2019: 350th Anniversary of Nicolaus Steno's Prodromus", where an early version of this paper was presented. My participation in that event was made possible by Montgomery College EAP funds. I am grateful to Stefano Dominici, Gary Rosenberg, and Victor Baker for their insightful comments and suggestions, which substantially improved the manuscript. Thanks also to Amy Cutler for preparing Figure 1.

\section{REFERENCES CITED}

Cutler, A. (2003) The Seashell on the Mountaintop, Dutton, New York, $228 \mathrm{p}$.

Descartes, R. (1644) Principia Philosophiae, Amsterdam. Apud Ludovicum Elzerverium.

Dominici,S. (2009) Steno, Targioni, and the two forerunners. Journal of Mediterranean Earth Sciences, 1: 101110.

Ellenberger, F. (1996) History of Geology, V. 1, Balkema, Rotterdam, 299 p.

Ellenberger, F. (1999) History of Geology, V. 2, Balkema, Rotterdam, $404 \mathrm{p}$.

Gould, S.J. (1984) The titular bishop of Titiopolis, in Hen's Teeth and Horses Toes, Norton, New York, pp. 69-78.

Gould, S.J. (1987) Time's Arrow, Time's Cycle, Harvard University, Cambridge, p. 222.

Hansen, J.M. (2009) On the Origin of Natural History: Steno's Modern, but forgotten philosophy of science, in The Revolution in Geology from the Renaissance to the Enlightenment (Ed: G.D. Rosenberg) Geological Society of America Memoir 23, Boulder, pp. 159-178.

Hutton, J. (1795) Theory of the Earth with Proofs and Illustrations, William Creech, Edinburgh, p. 567..
Lyell, C. (1833) Principles of Geology, V. 3, facsimile of first edition, University of Chicago Press, 1991, 398 p.

Oldroyd, D. (1996) Thinking About the Earth: A History of Ideas in Geology, Harvard, Cambridge, $410 \mathrm{p}$.

Smith, J. (2018) Thinking from Traces: Nicolas Steno's Palaeontology and the Method of Science, in Steno and the Philosophers (Eds.: R. Andrault, R., M. Lærke M.), Brill, Leiden, 2018, pp. 177-200.

Steno, N. (1667) Canis Carchariae dissectum caput in Steno, N. Elementorum Myologiae Specimen, Florence, Stella, p. 90-110. (English translation in Steno Geological Papers (Ed: G. Scherz) Copenhagen, O dense University Press, 1969, pp. 66-131.

Steno, N. (1669) De solido intra solidum naturaliter content dissertationis prodromus, Florence, Stella, 78p. English translation in Steno Geological Papers (Ed: G. Scherz) Copenhagen, Odense University Press, 1969, pp. 134-234.

Steno, N. (1675-1677) Ornaments, Monuments, Signs, Arguments in Steno Geological Papers (Ed: G. Scherz) Copenhagen, Odense University Press, 1969, pp. 249-267.

Toulmin, S. and J. Goodfield, The Discovery of Time, University of Chicago, Chicago, 1982, 280 p. 